\title{
Integrating international linguistic minorities in emergency planning at institutions of higher education
}

\author{
Amer Hamad Issa Abukhalaf ${ }^{1}$ (D) . Jason von Meding ${ }^{1}$ (D)
}

Received: 13 January 2021 / Accepted: 8 June 2021 / Published online: 16 June 2021

(C) This is a U.S. government work and not under copyright protection in the U.S.; foreign copyright protection may apply 2021

\begin{abstract}
Research concerning the behavior of international linguistic minorities at institutions of higher education during disasters is very limited. Many international groups suffer from discrimination based on language (linguicism) during disasters - their stories are not being told, and their voices are not being heard. The main objective of our study is to develop new knowledge about disaster-related behaviors of international linguistic minorities at institutions of higher education with a view toward enhancing overall campus emergency planning. Qualitative and quantitative methods were used to collect and analyze data; 62 subjects from the international community at University of Florida (UF), including foreign employees, international students, and foreign dependents, were surveyed shortly after the hurricane Dorian alert on campus. Additionally, 10 subjects from the UF international community were interviewed. The data analysis sought to provide insights into one main question: What were the key challenges facing international linguistic minorities at UF campus during the hurricane Dorian alert? Three comprehensive groups of challenges were found; disaster knowledge deficit and false perceptions, generic emergency communication, and inadequate disaster preparedness. The research findings provide insight into the experience of culturally different groups and offer practical and critical policy insights that help in developing more efficient disaster mitigation plans, and disaster risk-reduction strategies.
\end{abstract}

Keywords Emergency planning $\cdot$ Linguistic minorities $\cdot$ Campus $\cdot$ Linguicism $\cdot$ Risk management $\cdot$ Hurricane Dorian

Amer Hamad Issa Abukhalaf

amer.abukhalaf@ufl.edu

Jason von Meding

jason.vonmeding@ufl.edu

1 Florida Institute for Built Environment Resilience, University of Florida, Gainesville, FL, USA 


\section{Introduction}

Emergency planning at institutions of higher education is a very challenging task due to the significant number of potential threats (Kang 2018). Despite resources that can provide help in various disaster scenarios, gaps still exist in emergency planning within institutions of higher education (Boon et al. 2012). The impact of emergency planning failure goes beyond human injuries or property damage; it covers the psychological impact as well, such as depression and posttraumatic stress (Madden 2017). In a US conducted study, with a sample size of more than 400 volunteers from college communities, subjects reported higher levels of alcohol and drugs use in order to cope with posttraumatic stress due to insufficient awareness caused by communication failures during hurricanes Katarina and Rita (Prost et al. 2016).

The main duty for the administration at institutions of higher education is providing a safe environment for the college community (Sheldon 2018), and the biggest challenge here to overcome is having a communication system that is tailored around the needs of each and every group on campus, regardless the size of the group (Manoj and Baker 2007). Lack of trust, irrelevance, and inefficiency in message delivery are stressed regularly in disaster studies to explain why emergency communication sometimes fails (Patten et al. 2019). When a failure in emergency communication happens, marginalized groups tend to seek information through other sources, which increases the likelihood of misleading information and miscommunication (Sheldon and Antony 2018). Many disaster studies have proven that communication systems at US institutions of higher education lack customization and specificity (Watson et al. 2011). Unified communication carries a low operational cost (Abusal 2018), but in many cases, it is not the most effective one; when we unify communication, we risk creating a sense of rejection, as it was found in $20 \%$ of college community members who choose as a result not to be enrolled in disaster-related communication (Christal et al. 2019).

After the closure of almost 700 institutions of education in 2005, due to major hurricanes in the U.S (Esnard et al., 2018), many disaster scholars started to focus more on institutions of higher education (Findley, 2015). Several studies were successful in identifying subgroups within college communities that have different communication behaviors during disasters, such as the international linguistic minorities (Reed and Macuare 2019); however, these subgroups were usually viewed as homogenous entities with unified behavior (Uekusa \& Matthewman, 2017).

The ability to notify hundreds, if not thousands, about possible threats on campus in a timely manner is one of the core goals of campus emergency planning (Oktari et al. 2014). A study was conducted on eight institutions of higher education in Florida and showed considerable gaps in emergency planning even for institutions marked by the government as Storm-Ready. The problem was especially acute among international groups, who lack the basic severe weather knowledge (Reed and Macuare 2019). Moreover, international groups at institutions of higher education are usually overlooked in disaster studies (He 2007). In two studies, one conducted by Valencia Community College in Florida (Gutierrez et al. 2005), and another one conducted by University of Southern Mississippi (Coleman 2008), researchers studied the challenges of the educational continuity after disasters; however, international linguistic minorities were overlooked in both studies, and all the results were based on domestic groups only. Another study was conducted by University of South Florida, where 500 subjects were surveyed to study the psychological impacts of hurricanes on the college community, and international linguistic minorities 
were overlooked once again, and the results were generalized to the domestic ones (Simms 2013).

In this research, we study the behavior of international linguistic minorities, including foreign employees, international students, and foreign dependents, at US institutions of higher education. The main objective of this study is to identify challenges that face these international groups, focusing particularly on emergency planning and communication during severe weather events, in order to improve the overall campus disaster risk management.

\section{Literature review}

The accelerated international migration made linguistic minorities a global phenomenon (Uekusa 2009). A linguistic minority can be seen as a small community that chooses to speak a different language from the one spoken by the host country (Oliver and Exell 2020); however, these smaller communities find themselves under the pressure to linguistically adapt to the host country and usually have feelings of inferiority for not speaking the local languages well enough (Uekusa 2011). As a result, they develop social infrastructure and a linguistic landscape in which they use their own language among different cultural, political, and social events, where they avoid interaction with native speakers, in an attempt to escape language-based discrimination (Uekusa and Matthewman 2017).

Language-based discrimination (also called linguicism, linguistic discrimination, glottophobia, and languagism) is an unfair treatment based on the use of language and other characteristics of speech, such as having a different mother language (Jean-Pierre 2018). Based on differences in the use of language, people tend to automatically form judgments about a linguistic minority. Such judgments may relate to wealth, character, education, etc., which can lead to unfair treatment (Oliver and Exell 2020). Linguicism was studied in different contexts; social, political, environmental, educational; nevertheless, linguicism is rarely addressed in emergency planning and disaster studies, and even when it is addressed, it is commonly inappropriately analyzed (Uekusa 2019).

Language is the first and most important tool for emergency communication (O'Brien and Federici 2019). Not being able to distribute warnings and critical disaster information is a matter of life or death (Bodenreider et al. 2019). Hurricane Katrina hit Latin communities harder than any other ethnic community in the USA; most Latinos did not evacuate due to the fact that storm warnings were broadcast mainly in English (Méndez et al. 2020). For the same reason, another 30 Latinos died in 1987 when a tornado struck Saragosa, Texas (Uekusa 2018). And even after a sorrowful event takes place, the government agencies tend to fail in understanding vulnerabilities of disaster survivors among these linguistic minorities (Uekusa and Matthewman 2017), because not being able to tell their stories in their languages means that most likely they will not be heard (Uekusa 2020). Some sociolinguists argue that when stories are told, and history is written, they are narrowly focused on one small portion of speakers: the one with resources and power to control information distribution (Lippi-Green 2012).

The importance of including international linguistic minorities actively in emergency communication has been stressed through multiple past experiences (Gómez 2013), such as the Tohoku earthquake, Brisbane flood, and New Zealand 2011 earthquake, where 185 people died, many of which were particularly international students (Thorup-Binger and Charania 2019). The vulnerability of such minorities has been documented in several 
disaster studies, in which newly arrived and young members from these smaller communities were found even more vulnerable (Thorup-Binger 2018). International linguistic minorities face unique disaster vulnerability due to structural inequality, low socioeconomic status, limited access to resources, reduced social support, cultural differences, lack of disaster knowledge, and most importantly, disaster linguicism (Uekusa 2018).

Marginalized subgroups are often not included proactively in emergency planning at institutions of higher education (Méndez et al. 2020). International linguistic minorities might receive general information about disasters; however, the provided information focuses on basic preparedness for disasters and overlooks almost entirely the recovery process when a disaster happens (He et al. 2007). After being exposed to natural hazard, international linguistic minorities can experience depression, increased anxiety, and trauma; as a result of not having someone to communicate with or talk to, where having someone to talk to in their native languages during stressful times should not be seen as a privilege (Uekusa 2020).

International linguistic minorities at institutions of higher education have limited confidence and lower self-esteem when it comes to negotiating and asking for critical information during emergencies, or even for disaster relief aids when a disaster strikes (Franco et al. 2018). And because of that, these minorities are made to feel somehow responsible for their own limited language competency, which makes them also responsible for their own recovery, and eventually, blamed for not being able to ask for help in such circumstances (Chmutina et al. 2021).

Institutions of higher education focus on teaching the dominant language to international linguistic minorities (Qin and Li 2020), even when research shows that the most effective way for information accessibility in disasters is to provide information and services in different languages (Page and Chahboun 2019). Timely information during disasters is crucial to the well-being of people, and the role that language plays in diffusing relief information and disaster warnings is very critical in disaster preparedness and disaster response (St. Cyr 2005). Linguicism can be responsible for making critical disaster information inaccessible to some people, leading to a higher likelihood of devastating damages and fatalities (Uekusa and Matthewman 2017).

Previous disaster studies have already noted that 'language skills' are one of the major factors that contribute to social vulnerability (O'Brien et al. 2018), and the National Research Council specifically recognized warning dissemination as one of the main existing gaps in disaster research (National Academies Press 2011). Achieving effective communication and overcoming language barriers have become the central concern of many disaster studies (O'Brien and Federici 2019). However, current literature on the specific vulnerabilities and capacities of international linguistic minorities in the face of disasters remains very limited (Thorup-Binger and Charania 2019), causing a theoretical gap in the existing body of knowledge.

This study sheds a light on a research area that was not well researched before, which will contribute to an increased and better understanding of the complexity of disasterrelated behaviors for linguistic minorities in our communities generally, and within institutions of higher education particularly. This research gives us a real opportunity to study culturally different groups who are going through a serious life transition and offers practical and critical policy insights that help in developing more effective and efficient disaster mitigation plans, disaster risk-reduction strategies, and empowerment of international linguistic minorities. 


\section{Research method}

For the purpose of this study, we define international linguistic minorities as any group of nonresident aliens who live in the USA under work or study visa, and speak English as a second language. The main objective for this research is to develop new knowledge about these minorities at institutions of higher education in order to enhance the overall risk mitigation strategies, and the data analysis sought to answer one main research questions: What were the key challenges facing international linguistic minorities at UF campus during the hurricane Dorian alert?

In order to provide an efficient approach to flexibly explore the phenomenon under study, a mix of methods was chosen through two distinguished phases of data gathering and analyzing. Initially, questionnaires were completed by members of the UF international community on campus. This was followed by semi-structured interviews with members from the same international community who work or study at UF.

\subsection{Study location and recruitment}

The main campus of UF, located in Gainesville, was chosen to be the site of this study, due to the large size of the international community in this small city, which was exposed recently to a hurricane alert; hurricane Dorian. The emergency system at UF is controlled by the emergency management department which reports to the UF public and environmental safety department. The main task for the emergency management department is to coordinate with other departments on UF campuses across the state to provide them with a framework to respond to a variety of threats, including natural hazards. The emergency system focuses on Just-in-Time communication through different communication channels, such as UF website home page, emails, social media, etc. (University of Florida 2019).

There are 7,107 international primary visa holders at UF from more than 130 different countries around the world, where China and India count for two-thirds of the international community at UF (University of Florida 2019). The males' presence is higher than usual in this international community; $61 \%$ males and $39 \%$ females, ranging between 4 main visa types for study or work; F1, J1, M1, and H1 (University of Florida 2019). The numbers above do not include secondary visa holders, such as F2, J2, M2, and H2 visas, who are the dependents of the primary visa holder, as many people choose to come to the USA with their familiars: typically their partners and their children.

The questionnaires were filled by members from the international community who came to the UF international welcome center for visa-related matters during the time of data collection, which minimized bias toward study majors, class rank, and working departments and achieved a higher level of diversity among participants. Being at least 18-year-old visa holder, working/studying full time at UF and has met the UF English language proficiency requirements, were the inclusion criteria for the subjects of the questionnaires.

To reflect on the data collected and to have a deeper understanding of the results from the questionnaires, members from the UF international community with different cultural backgrounds were interviewed. To reach out to the interviewees, we had an announcement at the UF international welcome center. And in order to make the participation more diverse, also covering $80 \%$ of the international community ethnicities, we asked specifically for subjects from China, India, Latin America, the Middle East, South Korea, and Southern Africa, where the maximum number of participants from each country/region was limited by 3 participants, and the subjects' selection was based on first come, first 
served. Other inclusion criteria of the interviewees were that they have met the UF English language proficiency requirements, they were 18 years of age or older and were living in Gainesville during the last hurricane season of 2019.

We asked for interviewees specifically from China, India, and South Korea because these are the top three countries of origin for international linguistic minorities at UF, and they count for almost $70 \%$ of that community. On the other hand, countries with linguistic and cultural similarities were combined together in separate groups, such as the Middle East and Latina America.

\subsection{Sampling and data collection}

The data collection process started after the hurricane Dorian alert in late August 2019 (National Hurricane Center 2019) and lasted until April 2020. Hurricane Dorian was expected to strike Florida, which forced the UF administration to cancel classes on the first week of September 2019. The event provided us with rich content, where most of the interviews and questionnaire questions were related to this recent natural hazard. We believe that the lockdown, which was caused by COVID-19 during March 2020, affected the number of participants in the study; nevertheless, the process focused on the quality of the data rather than the number of participants, and continued until the data saturation was reached.

To assure an adequate sample size for the participants in the survey, a confidence level of $90 \%$ and a margin of error of $10 \%$ were taken into consideration to determine the sample size; a sample of 68 UF international community members. The questionnaire was constructed based on academic literature (Fellows and Liu 2015), and through consultation with two members from the UF international community. As a result, one question was revised for improved clarity, and another question was added to the psychological impact and communication section, to ensure the questionnaire achieves the research aim. The modified questionnaire included 19 questions and 11 sub-questions, divided into 4 main sections; demographics, hurricanes' general knowledge, emergency communication and psychological impact, and hurricane preparedness. Questionnaires took $10 \mathrm{~min}$ on average to be completed, where all questions were short and direct (see Appendix for more details on questionnaires).

Additionally, one-to-one semi-structured interviews were conducted with 10 subjects from the UF international community to provide us with more in-depth information and to reflect on the data collected from the questionnaires. Subjects who were interested in being part of the study were accepted after ensuring that the inclusion criteria were met. 12 subjects reached out to participate, but only 10 of them met the inclusion criteria. The other two subjects were not in Gainesville during the last hurricane season of 2019; they were international students who moved to Gainesville in January 2020.

The first 7 interviews were conducted in-person at first, and the other 3 interviews were conducted online due to the city lockdown following the spread of COVID-19 cases in Gainesville. The duration of each interview ranged from 30 to $60 \mathrm{~min}$. To ensure the interview questions addressed the study's aim, they were reviewed by two of the subjects, and their comments were taken into consideration for improved clarity. The interviews were recorded, summarized, and sent back to subjects for content approval.

All subjects who participated in the study, whether in the interviews or the survey, were asked to sign a consent - based on UF protocols before their participation, knowing that no identifiable data was collected throughout the different phases of the study. Representative 
quotes from the participants in the interviews were used with pseudonyms in order to protect the confidentiality of all the participants.

\subsection{Data analysis}

The collected data were analyzed qualitatively and quantitatively. Qualitative analysis was used to provide a better understanding of the research area and reflect the subjectivity of the human element in the study by focusing on factors that influence behavior, and variables that motivate change. The data collected were thematically analyzed through a continuous formation and reflection on themes informed by pre-existing theories in emergency management and disaster studies, in addition to a combination of coding, deductive and inductive, as the codes were informed by the interviewed subjects.

On the other hand, the quantitative analysis was based on a statistical breakdown of the collected data from the survey. By using SPSS and Excel software packages, different statistical approaches, including Visual data analysis (VDA) and Comparison of Means (COM), were used to quantify variables and uncover patterns to quantify behaviors, in a way that it can be generalized to various groups among the linguistic minorities at UF (Fellows and Liu 2015). While many demographics, such as gender, marital status, housing, can influence subjects' behavior, the analysis focuses particularly on Country of Origin for the subjects. The other demographics were excluded from this paper to keep the scope achievable for one research paper. The ethical approval for this research was obtained by the UF-IRB (Institutional Review Board), reference number IRB201902598.

\section{Results}

\subsection{Questionnaires}

As per the agreement with the administration of the UF international welcome center, the location of data collection, we had 3 weeks to post the survey and collect as much participation as possible. The participation in the survey was less than expected, and we could not collect the 68 questionnaires to ensure the $90 \%$ confidence level for the sample size; however, with 62 completed questionnaires that we were able to collect, the difference in confidence level is less than $3 \%$, which should not devalue the findings. A total of 62 participants from the UF international community were surveyed, with an average age of 26 years for the subjects. The sample had a high level of ethnic diversity, and the subjects had an average of 34 months of Florida residency (see Table 1).

\subsubsection{Hurricanes' general knowledge}

The 62 subjects were asked if they knew the difference between hurricane-watch and hurricane-warning, and (41.9\%) of the subjects answered Yes; however, some subgroups showed higher levels of variation in answers (see Table 2). Then, the subjects were asked to identify the start and end of Florida hurricane season, and only (11.0\%) of the subjects were able to, and also here some subgroups showed higher levels of variation in answers (see Table 2). Finally, the subjects were asked about the possibility of a hurricane striking Gainesville in order to connect this perception to their behavior. The average of the sample 
Table 1 Demographic characteristics of subjects

\begin{tabular}{lr}
\hline Subjects $(N=62)$ & \\
\hline Birth gender & 28 \\
Male & 34 \\
Female & \\
Region/Country of origin & 25 \\
China & 11 \\
India & 9 \\
Latin America & 12 \\
Middle East & 5 \\
Others & \\
Housing & 10 \\
On-campus & 52 \\
Off-campus & \\
Marital Status & 51 \\
Single & 11 \\
Married & \\
\hline
\end{tabular}

Table 2 Study sample Avg. answers for the questionnaire's (Hurricanes' General Knowledge) section

\begin{tabular}{llcl}
\hline Region/Country of origin & $\begin{array}{l}\text { Familiarity with hur- } \\
\text { ricane language }(\%)\end{array}$ & $\begin{array}{l}\text { Florida hurricane season } \\
\text { start and end }(\%)\end{array}$ & $\begin{array}{l}\text { Possibility of } \\
\text { hurricane striking } \\
(\%)\end{array}$ \\
\hline China $(\mathrm{n}=25)$ & $28.0^{1}$ & 12.0 & 29.0 \\
India $(\mathrm{n}=11)$ & 36.3 & $0.0^{3}$ & $25.0^{1}$ \\
Latin America $(\mathrm{n}=9)$ & $55.5^{1}$ & $22.2^{3}$ & $43.0^{1}$ \\
Middle East $(\mathrm{n}=12)$ & 50.0 & $16.6^{2}$ & 36.0 \\
Others $(\mathrm{n}=5)$ & $0.0^{3}$ & $50.0^{1}$ \\
Sample Avg. $(\mathrm{N}=62)$ & $80.0^{3}$ & $\mathbf{1 1 . 0}$ & $\mathbf{3 4 . 0}$ \\
\hline
\end{tabular}

\footnotetext{
${ }^{1}$ The value falls outside the first range; (Sample Mean $\pm 25 \%$ )

${ }^{2}$ The value falls outside the second range; (Sample Mean $\pm 50 \%$ )

${ }^{3}$ The value falls outside the third range; (Sample Mean $\pm 75 \%$ )
}

was (34\%), and the variation of the answers between the subgroups was relatively low (see Table 2).

\subsubsection{Psychological impact and emergency communication}

When the subjects were asked about the anxiety caused by the Dorian hurricane alert, the sample had an average of (33.8\%) for the anxiety level, and some subgroups showed considerably lower averages in comparison with the sample average (see Table 3). Then, the subjects were asked about the overwhelmedness caused by UF hurricane communication, 
Table 3 Study sample Avg. answers for the questionnaire's (Psychological impact and Emergency communication) section

\begin{tabular}{lllll}
\hline Region/Country of origin & Anxiety level $(\%)$ & $\begin{array}{l}\text { Overwhelmed- } \\
\text { ness }(\%)\end{array}$ & $\begin{array}{l}\text { Over-communi- } \\
\text { cation }(\%)\end{array}$ & Satisfaction level \\
\hline China $(\mathrm{n}=25)$ & 38.7 & 29.2 & 47.2 & 68.9 \\
India $(\mathrm{n}=11)$ & $18.2^{3}$ & $48.4^{1}$ & $86.5^{2}$ & 84.7 \\
Latin America $(\mathrm{n}=9)$ & 38.2 & 34.7 & $0.0^{3}$ & 62.9 \\
Middle East $(\mathrm{n}=12)$ & $45.9^{1}$ & 31.5 & $86.1^{2}$ & 76.8 \\
Others $(\mathrm{n}=5)$ & $15.6^{3}$ & 28.9 & $1.7^{3}$ & $52.8^{1}$ \\
Sample Avg. $(\mathrm{N}=62)$ & $\mathbf{3 3 . 8}$ & $\mathbf{3 3 . 7}$ & $\mathbf{5 1 . 2}$ & $\mathbf{7 1 . 4}$ \\
\hline
\end{tabular}

${ }^{1}$ The value falls outside the first range; (Sample Mean $\pm 25 \%$ )

${ }^{2}$ The value falls outside the second range; (Sample Mean $\pm 50 \%$ )

${ }^{3}$ The value falls outside the third range; (Sample Mean $\pm 75 \%$ )

and the sample had an average of $(33.7 \%)$, where the variations in the answers were relatively low for this question (see Table 3).

To evaluate the over-communication in the UF emergency system, the subjects were asked about the communication channels they prefer vs. the ones actually used by UF. The average over-communication for the sample was $(51.2 \%)$, and several subgroups showed higher levels of variations in answers (see Table 3). And when the subjects were asked about the satisfaction level when it comes to the UF hurricane alert system, the sample average was (71.4), with a small variation in answers between the different subgroups (see Table 3).

\subsubsection{Hurricane preparedness}

When the subjects were asked about the locations of shelters at UF, only (22.6\%) of the sample knew where the shelters are; however, different subgroups showed higher variations in answers (see Table 4). The subjects were also asked about their perception of

Table 4 Study sample Avg. answers for the questionnaire's (Hurricane preparedness) section

\begin{tabular}{lllll}
\hline Region/Country of origin & $\begin{array}{l}\text { Shelters loca- } \\
\text { tion }(\%)\end{array}$ & $\begin{array}{l}\text { Perception of readi- } \\
\text { ness }(\%)\end{array}$ & $\begin{array}{l}\text { Emergency } \\
\text { kit }(\%)\end{array}$ & $\begin{array}{l}\text { Online } \\
\text { training } \\
(\%)\end{array}$ \\
\hline China $(\mathrm{n}=25)$ & 20.0 & 47.1 & 58.7 & 64.9 \\
India $(\mathrm{n}=11)$ & $36.4^{2}$ & 46.4 & 70.5 & $51.4^{1}$ \\
Latin America $(\mathrm{n}=9)$ & 27.8 & 45.7 & 50.1 & 65.3 \\
Middle East $(\mathrm{n}=12)$ & $8.3^{3}$ & $66.7^{1}$ & 71.5 & 63.9 \\
Others $(\mathrm{n}=5)$ & $37.5^{2}$ & $63.9^{1}$ & 59.8 & $93.3^{1}$ \\
Sample Avg. $(\mathrm{N}=62)$ & $\mathbf{2 2 . 6}$ & $\mathbf{5 1 . 1}$ & $\mathbf{6 1 . 6}$ & $\mathbf{6 4 . 6}$ \\
\hline
\end{tabular}

\footnotetext{
${ }^{1}$ The value falls outside the first range; (Sample Mean $\pm 25 \%$ )

${ }^{2}$ The value falls outside the second range; (Sample Mean $\pm 50 \%$ )

${ }^{3}$ The value falls outside the third range; (Sample Mean $\pm 75 \%$ )
} 
readiness during the Dorian hurricane alert. The sample average was $(51.1 \%)$, but variations of answers between the different groups were small (see Table 4).

Additionally, the subjects were asked to mark the items on the emergency kit which they had during the Dorian hurricane alert (see Appendix for more details), where subjects received one point for every checked item on the list. With a total of 11 items, a score of 11 represented the highest level of preparedness, while zero was the lowest. Then, the scores were changed into percentages. The sample average was $(61.6 \%)$, and the average scores for all the different subgroups were very close to the sample mean (see Table 4). Finally, when subjects were asked if they think that online hurricane training would be helpful, the sample average was (64.6\%), and variations in answers among the different groups were relatively small (see Table 4).

\subsection{Interviews with members from the UF international community}

Through a thematic analysis, the interviews resulted in 24 subthemes, under five main themes of challenges; lack of support in the transition phase, daily challenges, emotional challenges, hurricane season challenges, and communication challenges (see Table 5).

Table 5 Themes identified from interviews with subjects from the UF international community $(\mathrm{n}=10)$

\begin{tabular}{|c|c|}
\hline Themes & Associated sub-themes \\
\hline Lack of support in the transition phase & $\begin{array}{l}\text { Hardship in admission and visa processes } \\
\text { Securing housing opportunities } \\
\text { Issuing legal documents } \\
\text { Timing and design of orientation sessions } \\
\text { Lack of awareness about UF resources and services }\end{array}$ \\
\hline Daily challenges & $\begin{array}{l}\text { Financial concerns } \\
\text { Cultural differences } \\
\text { Language barriers } \\
\text { Social networking } \\
\text { Transportation }\end{array}$ \\
\hline Emotional challenges & $\begin{array}{l}\text { Overwhelmedness and Homesickness } \\
\text { Lacking a sense of security } \\
\text { Stress and anxiety } \\
\text { Lack of mental health awareness }\end{array}$ \\
\hline Hurricane season challenges & $\begin{array}{l}\text { Lack of Hurricane Basic knowledge } \\
\text { Wrong perceptions } \\
\text { Hardship in securing emergency kits } \\
\text { Lack of trust in government } \\
\text { Safety of accommodations } \\
\text { Over-reacting } \\
\text { Heterogeneity of the international community }\end{array}$ \\
\hline Communication challenges & $\begin{array}{l}\text { Over-communication and Lack of coordination } \\
\text { Translation issues } \\
\text { Using wrong communication platforms }\end{array}$ \\
\hline
\end{tabular}




\subsubsection{Lack of support in the transition phase}

The struggle of the UF linguistic minorities starts before they even come to Gainesville. From satisfying admission requirements, to securing a contract, and then applying for a US visa. Not only that costs a lot of money, but also the process can take months. During that period, the university's support to the linguistic minorities seems to be inadequate.

I got the acceptance letter from UF late, which affected my Visa application, so I got my Visa two days before the start of the semester! and UF did not provide any guidance through the process. I got to the U.S. late, and I missed the orientation sessions. (Alex, Interviewee).

After arriving at Gainesville, many of the linguistic minorities struggle in finding housing because housing in Gainesville is very competitive, especially for on-campus housing, and the university does not help in that matter. As a result, most of them end up living far away from campus. The international linguistic minorities at UF are also required to issue certain legal documents in order to start their jobs, such as State ID and SSN, and they are expected to go through the process by themselves with no help from any of the UF offices.

I needed to apply for SSN before I get paid from my job at UF. I did not get help from the university, and I found the process very difficult! Then I had to wait for two months before getting paid, and during that time, I was spending money from my own pocket. (Jeramy, Interviewee).

I learned not to ask for help from any of the offices at UF, because you get a sense that there is a distance that people expect from you, where people need their space and they want to be left alone, and you need to figure out things on your own! (Riley, Interviewee).

If they got lucky with the visa and arrived ahead of time to Gainesville, international linguistic minorities get the chance to attend the UF orientation sessions that takes place at the very beginning of each academic year. The same sessions are given to everyone on campus whether they are domestic or international. The sessions tend to have an administrative theme, where the university explains the rules and regulations on the UF campus and does not cover any specific topics for the international community.

I found the orientation sessions very administrative! It didn't mention any cultural challenges or discuss the natural hazards in Florida. And these topics are very critical and need to be covered! (Erin, Interviewee).

The university has many resources, but they don't advertise it well. They should be more vocal about such resources and services. Many people don't even know that these services are for free, and that's why they don't approach them! (Kim, Interviewee).

\subsubsection{Daily challenges}

International linguistic minorities experience many challenges when they move to Gainesville. Living expenses in the USA generally are high compared to other countries like China and India, and it is even higher in Florida compared to other states in the USA, which seems to take many of them by surprise when they arrive at Gainesville. At the same time, getting adjusted to the new life and absorbing any cultural shocks require a fair 
amount of time that could vary from country to another, and also from one individual to another.

I was spending around $\$ 300-\$ 400$ at least from my pocket every month because I was not paid enough money! The amount of money that the school pays is not structured on real-life expenses at Gainesville, which forced me to make bad life choices, like relying on cheap fast food, to be able to cope with new life. (Alex, Interviewee).

I think being conservative generally works against you in this country. The more connected to my faith I became, the UF environment got less friendly. Besides, the U.S. society is a racialized society; being a dark-skin female from Africa disqualifies you in many different ways here, especially on a social level. Skin color is something that you always need to be aware of in the U.S., and I find it emotionally toxic. (Riley, Interviewee).

Many of the primary visa holders who come to work or study at UF are required to have a high level of English language proficiency. Nevertheless, the dependents of the primary visa holders are not required to have any level of English language proficiency, and the university is not obligated to support any of them in any way, knowing that the university communicates with them only through the primary visa holder, especially that most of them live off-campus.

The biggest problem for my family was the language, especially for my 7 years old kid who still struggles at his primary school. Even my wife had to take an English course to improve her language in order to move around the city. (Sam, Interviewee).

I believe getting used to speaking English all the time is one of the biggest challenges that South Koreans face here in the U.S., this is why you find us spending most of our time together. And I believe that language barriers are the main reason why we don't ask for help from others on campus. (Jaime, Interviewee).

Compared to other college towns, Gainesville is fairly crowded, and not having a car to move around the city can be problematic. The main public transportation system in Gainesville is the RTS bus system, which is very efficient when it comes to moving people in and out of campus; however, it is very limited in connecting the other parts of the city together. Additionally, most of the RTS bus routes are not available after sunsets, Sundays, and during holidays, and they work half capacity during the summer.

The transportation system here is very limiting. You feel like the whole country is set up in a way where you need to get a car to go almost anywhere. I personally ended up buying a car shortly after I moved to Gainesville. (Drew, Interviewee).

\subsubsection{Emotional challenges}

Being thousands of miles away from their countries can have a significant emotional impact on the linguistic minorities at UF. Being in the USA with a study or work visa puts a lot of pressure on people as visa requirements tend to be very strict and sometimes overwhelming. For example, ESL students who come to learn English are expected to have 23 credit hours per semester to maintain their visa status. As a result, many of them prioritize career and academic deliverables over a healthy social life, which why many of them struggle and feel overwhelmed and homesick. 
The first few weeks at UF can be very overwhelming. When I checked the on-campus housing, it was insanely competitive, and almost impossible to secure a spot oncampus. I was so lost and homesick, and I thought seriously about quitting everything here and just going back home. (Alex, Interviewee).

My first impression when I got to Gainesville was that I had no sense of security. When you don't have a place to stay, and the university doesn't help in finding one, you feel powerless! (Erin, Interviewee).

In times of emergencies, such as the hurricane season, stress and anxiety levels for the linguistic minorities might increase significantly, as many of them have no previous experience with severe weather hazards, such as hurricanes. And while they might be struggling mentally and emotionally, some do not know how to deal with it, where cultural differences can play a big role here in seeking mental help.

During hurricane Dorian, I was home alone for 4 days and had no idea what would happen. I was confused because local people on campus were not worried at all, but the university communications had a very serious tone, and they kept sending emails! There was too many of them, and I honestly got to a point where I stopped reading the emails, because it was very stressful. (Angel, Interviewee).

There are many different reasons to get you stressed as an international student in the U.S.! you are expected to be a good student who considers school a priority at the expense of anything else, where mental health is something that is not necessarily considered as a real factor. You are expected to pull yourself together, and figure things out. (Riley, Interviewee).

\subsubsection{Disaster preparedness challenges}

Florida has a hurricane season that starts in June and ends in November of every year. And while this is a part of the locals' life, many of the linguistic minorities have no previous experience when it comes to hurricanes, and even for some, they do not know what to expect from such a natural phenomenon. And of course, the behavior might vary a lot from one linguistic group to another, based on what part of the world they come from.

When my family and I moved to Florida, we had no idea about the hurricane season, and the university didn't share any information about this with us before we came to Gainesville. When we first arrived, my friend who lives here explained some details to us about the hurricane season and how to prepare for it. (Sam, Interviewee)

After living here for 6 years, I still don't know the difference between cyclones and hurricanes, but I imagine hurricanes to be more severe and more destructive, and this purely based on what I see from the government and people reaction to hurricanes in the U.S. compared to how we react to cyclones back in India. (Drew, Interviewee)

Based on the direction of the emergency management department, the UF community is asked during the hurricane season to have an emergency kit that has basic supplies, such as food and batteries. And while most of the items are easy to secure on a normal day, when there is a hurricane approaching, the local stores run out of essential supplies very fast, and while the local people know that in advance, international linguistic minorities, especially the newly arrived ones, end up with very little to face the natural hazard with. 
One problem that I noticed is when there is a hurricane approaching, people overreact and grocery shops become out of supplies, and many of us end up with no food or water, and that is a problem! (Erin, Interviewee)

Like many other cities in Florida, Gainesville is a flood-prone area. Living on ground floors in Gainesville carries the risk of being flooded, and while the local people are aware of that risk, many of the linguistic minorities are not. It is not also unusual to lose power in Gainesville during storms. Some linguistic groups view this as dereliction from the city and the government, especially for Asian minorities who compare the situation to the performance of their governments in such circumstances, where losing power is almost unheard of in their countries.

When I got here, I noticed water damage in first floors of buildings around the campus, so I made sure to get an apartment that is at least a second floor. (Angel, Interviewee)

I don't know the difference between storm warning, watch, and alert, or the difference between a hurricane and a tornado, I honestly expect rainy and windy weather in all of them. I never felt like I need to know the difference back home because I trusted the Chinese government in dealing with such emergencies. On the other hand, I don't trust the government here! I remember once people in Gainesville lost power due to a thunderstorm! Such things would never happen in China. (Ashton, Interviewee)

The UF international community is a heterogeneous community with many groups from completely different backgrounds, which makes their behaviors vary, especially during disasters. While some may panic from a rainstorm, others have survived major cyclones and typhoons back home. Besides the previous experience of severe weather hazards, cultural differences can have a great influence on the behavior of the different international groups.

Since I moved here in 2016, I think I have changed a lot! I used to be an eastern young man, who is filled with ego and ignorance, and I would never consider seeking help for mental health, but now I am willing to get the right help from school if I find myself under pressure that I can't tolerate. (Erin, Interviewee)

I believe that there is little information shared about hurricanes from the university. I personally picked up the attitudes towards hurricanes from the locals who seem to be less concerned about it. (Riley, Interviewee)

\subsubsection{Communication challenges}

One of the challenges at large institutions of higher education, such as UF, is to have an effective level of internal communication with all different college groups on campus, as well as off campus. UF uses multiple communication platforms to reach out to its community members, and that sometimes causes an over-communication problem, especially for the international community who receive the same communication repeated over and over by different departments across the campus, which can cause a sense of rejection and force people to look for information from less trusted sources.

I usually don't read the emails from school because they tend to send too many emails, and most of the time it is general information that does not apply to me. For 
example, I keep receiving emails related to F1 visa holders, and I carry a J1 visa! (Kim, Interviewee).

I think there is a huge coordination gap between UF offices around campus, especially the ones who work on common matters. They function separately like they are completely different entities; it can be a real mess sometimes! (Alex, Interviewee).

The university uses one language in communicating with students and staff, the English language, and expects everyone on campus to get and comprehend the messages on the same level, including the linguistic minorities who do not speak English as a mother language, and who might rely on direct translation to understand the content of these messages, which does not take the context of a language into consideration, leading to a great deviation in understanding

I always face problems when it comes to the language used in emergency communication. For example, Hurricane is translated to Persian as (طوفان) which is translated back to English as a rainstorm! Tornado is translated to Persian as (كَ) (طبان) which is translated back to English as a whirlwind. So translation doesn't help me much to get a good understanding of what is happening. (Angel, Interviewee)

\section{Discussion}

While the data gathered may have awakened new questions about human behavior during emergencies and in times of disasters, our analysis was designed to provide insights into one main question concerning hurricanes and institutions of higher education: What were the key challenges facing the international linguistic minorities at UF campus during the hurricane Dorian alert?

\subsection{Disaster knowledge deficit and false perceptions}

The orientation sessions at UF cover a wide range of topics, such as financial aids, legal information, school resources. These sessions are offered by UF to newly-arrived members during August and September, which happens to be the peak of hurricane season in Florida. However, three out of the ten who participated in the interviews arrived at Gainesville after the orientation sessions had taken place, due to late responses from the university in their admission phase. The university seems to underestimate the time needed for the visa application in some cases. At the same time, the content of these orientation classes is not shared again at any later point with anyone who missed it, leaving many of the international linguistic minorities unaware of the resources that can help when a natural hazard approaches.

Based on the data we collected, we also found that the international community at UF lacks the basic knowledge about severe weather hazards, and hurricanes in particular. For example, $(11 \%)$ of the sample only was able to correctly identify the start and the end of the hurricane season, and only $(22.6 \%)$ of the sample knew the location of shelters at UF (see Tables 2 and 4). And even that Gainesville is known to be a flood-prone, and many of the first-floor apartments in the city at a higher risk of being flooded (Alachua County 2020), only two of the ten participants in the interviews were aware of these facts, and took flooding as a consideration when they made accommodation arrangements. If 
the UF administration wants the international community to adopt healthy disaster-related behaviors, they need to overcome this knowledge deficit, keeping in mind that knowledge availability may not guarantee behavioral change, but lack of knowledge prevents it for sure from happening (Tran 2020).

Additionally, our data show that some linguistic minorities rely on their past experiences in their home countries and they prepare for the Florida hurricane season in the same way. While that might be expected, the UF administration should be aware of how that can go wrong. Two of the subjects who participated in the interviews explained how they prepared for hurricanes in the same way they would have prepared in their home country, China. However, they were surprised since what they did was not enough. Losing power and water during hurricanes in the USA is common and expected, but this is unheard of in China based on the participants, who did not buy water or any source of power, like batteries, not considering power and water loss even a possibility. This explains the lack of trust that some of the participants had in the US government when it comes to preparing and responding to natural hazards.

The protection motivation theory, which predicts people's behavior during emergencies, considers risk perception as the first factor that influences people's disaster-related behaviors (Tang and Feng 2018). Our data show that the international community at UF has an inaccurate and much higher perception of hurricane striking possibility in the Gainesville area (see Table 2), which explains why some of them might overreact during the hurricane season, leading to higher levels of stress and anxiety among these linguistic groups (see Table 3).

Furthermore, many of the linguistic minorities view the hurricane season with a cultural lens, they look at the local reaction to natural hazards and compare it to the reaction to similar hazards in their home countries (Abukhalaf and von Meding 2021a). For example, we found from the interviews that many of the linguistic minorities think that hurricanes are more severe than typhoons and cyclones, based solely on the way local people act in Florida. Finally, when the subjects were asked about their perception of personal readiness during the hurricane season (see Table 4), the sample average was (51.1\%), which reflects a mature understanding of the status quo and shows that they realize that they are not well-prepared. The UF administration should take advantage of this sense of maturity and reeducate the international community to correct their perceptions when it comes to the severity and frequency of hurricanes in the Gainesville area.

\subsection{Generic emergency communication}

During the hurricane season, the university uses unified communication to reach the entire UF community and does not take specifically into consideration the different groups on campus, including the international linguistic minorities. Previous studies show that the international communities at institutions of higher education respond differently to emergency communication (Abukhalaf and von Meding 2020). The data collected in this study also suggest that the international communities at institutions of higher education are not homogenous. The survey showed distinctly different disaster-related behaviors based on country of origin, where significant statistical variations were found in the answers among the different linguistic groups at UF (see Tables 2, 3 and 4).

Not having a customized emergency communication pushes the UF administration to rely on message repetition using multiple platforms in order to reach out to everyone on campus (Schwalbe 2016), which may not be the best way to approach this (Miller 1963). 
The over-communication level reported by the 62 participants in the survey was $(51.2 \%)$, and over-communication and lack of coordination were found among the main communication challenges reported by the participants in the interviews. The university might believe that more is better, but that does not necessarily apply to emergency communication (Gordon et al. 2017).

Over-communication can cause several and serious complications, such as creating a sense of rejection for the message and losing sense of urgency (Abukhalaf and von Meding 2021a). The participants in the interviews considered over-communication as a main cause for increasing levels of anxiety and overwhelmedness during the hurricane season (see Table 3). Based on the data collected from the interviews, over-communication is largely caused by lack of coordination between the different UF departments on campus. Many of the big public universities in the USA, such as UF, rely on decentralized communication systems, and that can be problematic (Watson et al. 2011). For example, during the hurricane season, the international linguistic minorities can receive the same message from the UF department of emergency management, the UF office for international services, the dean office, the direct college department, etc.

When messages travel in such sequences, there is a new chance for message distortions at every repetition (Miller 1967). Message distortions can create confusion among international linguistic minorities on campus, especially when they find contradictions in the content of the messages. Contradicting messages can also lead to contradicting behaviors among the different linguistic groups, which jeopardizes the trust in the university communication system as a whole (Findley 2015).

In addition to emails, and text messages, the university uses different social media platforms, such as Facebook and Twitter. While these social media platforms are well-known and used by the majority of people in the USA, many international linguistic groups use alternatively foreign platforms. Through the interviews, we found that most of the international Chinese community on campus relies heavily on WeChat to look for and share information, at the same time, Kakao was the most used application for the South Korean community on campus. To make the emergency communication process more successful, the university needs to be more knowledgeable about the different groups on campus and tailor the communication system around them (Sheldon 2018). The linguistic minorities need to receive emergency messages through platforms that they are using already (Abukhalaf and von Meding 2021b).

Like the majority of the US colleges, UF uses only English in emergency communication; however, international linguistic minorities, by definition, have limited understanding of the English language, especially the groups that are not required by UF to have any level of language proficiency, such as ESL students. Previous literature suggests that linguistic minorities who have higher levels of English proficiency might still be unfamiliar with the technical language used in emergency communication (He 2007), which supports our findings in Table 2.

International linguistic minorities may not be able to fully comprehend the disaster terminology used in emergency communication (Chmutina et al. 2020). The terms used in UF emergency communication is the same one used in local weather channels, so the domestic groups find it easy to understand; however, the linguistic minorities find it challenging (He et al. 2007). Based on the interviews, most of the participants were confused by the terms used in UF emergency alerts. Many of them did not know that hurricanes are the same as typhoons and cyclones. Also, many of them did not know the difference between hurricanes and tornados, where they expect rain and wind in both of them, and prepare for them the same way. 
In the survey, when the subjects were asked about the familiarity with hurricane language, more than half of the sample was found unfamiliar with the terminology used by UF in emergency communication during the hurricane season (see Table 2). And through the interviews, only two out of the ten participants experienced natural hazards back in their countries. So for the rest, the English language was not the only problem; some participants were unfamiliar with the terminology used in emergency communication even in their mother languages, because they never experienced similar circumstances in their life.

On the other hand, switching between languages is not an easy task (Tao 2019), and previous studies have shown that cognitive processes are affected by the language we use (Athanasopoulos 2007). Other studies have shown that second language processing is also affected by the way we feel at the moment (Thierry 2016). Basic reading tasks can be affected by our psychological status (Martin et al. 2013). And when we combine both factors, second language processing and psychological status, we find that international linguistic minorities face a greater challenge to understand emergency communications during stressful times (Volk et al. 2014).

\subsection{Inadequate disaster preparedness}

The biggest and most common problem that linguistic minorities face after arriving at Gainesville is securing housing opportunities. Even that Gainesville is considered relatively a small city, the housing in Gainesville is very competitive, especially around the midtown area, where UF main campus is located (O'Neill 2020). Securing a housing opportunity close to campus can take months of searching, and because international linguistic minorities are only allowed to be in the U.S only one month before the start of their job/study (University of Florida 2019), the majority ends up living in off-campus housing and far away from the UF campus. At the same time, transportation is a major limitation for international linguistic minorities living away from campus.

Transportation is a critical element for the safety of international linguistic minorities during disasters (Thorup-Binger \& Charania, 2019). As mentioned before, Gainesville Regional Transit System (or RTS) is the only local transit corporation serving the city. Usually, there are around 40 city routes, 10 of them are UF campus routes. During the weekdays, all the city routes stop after $8: 30 \mathrm{pm}$, except for 5 routes, and on the weekends, there are 16-19 routes working from the original 40 routes (Regional Transit System 2020). The waiting time for a bus ride can range from 5 to $60 \mathrm{~min}$, and while that might be tolerated in normal days, during disaster evacuations, it is unacceptable, as every minute can be a matter of life or death. Not having a reliable transportation system might be also a reason for not securing the items on the personal emergency kit. Our data show that the emergency kits completion average for the sample was around (60\%), which means on average, each subject did not have 4 items from the original 11 that UF requests them to have during the hurricane season (see Table 4), and these numbers should be concerning to the UF administration.

Living expenses are among the biggest challenges that take many of the international minorities by surprise when they arrive in the USA (Franco et al. 2018). While many of them expect the income they receive from UF to be structured on the living expenses in Florida, and particularly in Gainesville, they find out the opposite. Many international families end up in a severe cost-burdened, as they spend more than $50 \%$ of their income on rent, which affects their ability to prepare for hurricanes, as stocking food and water, and 
securing the rest of the items on the emergency kit checklist can be unaffordable to many of them.

Before signing a housing contract and having an official mail address, opening a US bank account and issuing other legal documents, such as State ID and SSN, is almost impossible (Alachua Collector 2020). Until the international minorities get their SSNs, they might have to wait for six weeks (US Social Security 2020). This means they will not be paid for almost two months from their arrival to Gainesville, which makes the first few months in Gainesville financially overwhelming. During that phase, the university does not provide any official support, and the international minorities are expected to work things out by themselves. And instead of being excited and motivated about the new life experience, many of the international minorities end-up feeling stressed, confused, and lost at a very early phase of their UF journey. Not having the expected support from the university leads to a lack of sense of security, which makes many of them consider quitting and going back home within the first few weeks from their arrival to the USA.

For international linguistic minorities, moving to the USA can be a significant life experience that is financially, emotionally, and mentally overwhelming (Uekusa 2019). And while they might be going through hard times, many of them are not willing to ask for professional help, especially when it comes to mental health. Some of the subjects interviewed described going to a psychiatrist as a 'waste of time'. We found that one subject, in particular, travels overseas twice a year to be with family and friends, as a mechanism to deal with stress. Many of the linguistic minorities are still living in the shadows of their cultures, even after settling down in Gainesville. Our data show that males particularly are expected to be strong and independent all the time, and seeking help from others can be seen in some cultures as a sign of weakness, which greatly impacts their behavior during emergencies, as they may not know what to do or where to go, but still insist to figure things out by themselves, leading to wrong disaster-related behaviors that can be life-threatening for them and for the people around them.

\section{Limitations and future research}

Before analyzing the data, we excluded some demographics due to the size of the collected data. Consequently, our findings did not take into consideration marital status, children, gender, and accommodation, which could have given better insights into our findings. We also did not include ESL students in the study, neither we took into consideration any participant's disabilities in the data our data collection and analysis, which could have added a new dimension to the study, especially with regard to Sign-Language. Additional comparative studies should be conducted in the future to better understand the influence of the other demographics on the behavior of international linguistic minorities at institutions of higher education.

In order to achieve a confidence level of $90 \%$ and a margin of error of $10 \%$, we needed 68 participants in the survey; however, after excluding the incomplete questionnaires, we had only 62 completed ones. With the same margin of error, the confidence level for the available data is around $87.5 \%$. The difference between planned and actual confidence levels is less than $3 \%$, which should not devalue our findings. However, additional surveys should be conducted in the future with higher confidence levels, in order to be able to generalize the findings to the UF international community. We also believe that the city and campus lockdown due to Covid-19 affected the number of participants in the interviews. 
Additional interviews should be conducted with members of the UF international community to complement the findings in the paper.

Our findings are specific to the context of hurricane Dorian and UF campus, and they are not representative of other institutions of higher education across the state; nevertheless, they provide new insight into this new area of study and have awakened new questions about the human behavior during disasters, which creates new opportunities for future research, especially in two main areas. First, the international community at UF is a heterogeneous community with many groups from different cultural backgrounds. Our data show great variations in the answers between the different international groups, especially in hurricanes' general knowledge and the psychological impact of hurricanes on individuals. Additional comparative studies should be conducted in the future to explore the differences between the various groups within the UF international community. Second, the interviews provided great insight into the challenges faced by international linguistic minorities at UF, especially for social networks and financial readiness. Nevertheless, we did not have enough data from the survey to explore that, which makes this area a very interesting subject for future research.

\section{Conclusions}

Research concerning disaster preparedness at institutions of higher education is limited, especially with regard to international linguistic minorities (Thorup-Binger 2018). What makes emergency planning a challenging task within institutions of higher education is the lack of research from the perspective of the different groups on campus (Tkachcuk et al. 2018). The majority of international linguistic minorities suffer from disaster linguicism, as their stories are not being heard and their distinctive needs are not being taken into consideration within campus emergency planning. The main objective of this study is to develop new knowledge about the behavior of international linguistic minorities at institutions of higher education, and integrate that knowledge in campus emergency planning, in order to enhance the university's overall disaster risk management.

Different methods were used for collecting data; 62 subjects were surveyed from the UF international community shortly after the hurricane Dorian alert on campus. Moreover, ten subjects from the international linguistic minorities at the UF campus were interviewed. Our findings provided insights into one main research question: What were the key challenges facing international linguistic minorities at the UF campus during the hurricane Dorian alert? 24 subthemes were identified (see Table 5) and discussed in detail under three comprehensive groups of challenges: Disaster knowledge deficit and false perceptions, generic emergency communication, and inadequate disaster preparedness.

In order for the UF administration to have effective emergency planning, the university must realize the behavioral distinction of each group during emergencies (Teo et al. 2019) by taking into consideration the input and insight of all the different groups on campus in the process (Abusal 2018) Moreover, to maximize the benefit from proactive emergency planning, regular studies should be conducted to find new effective ways to actively involve all the different groups in the emergency planning crafting process (Esnard et al. 2018), making the success of the process a shared responsibility between the UF administration and entire UF community (Shaw 2016). 


\section{Appendix}

\section{Questionnaire for research entitled "Bridging the Gap: Communication challenges in UF emergency planning IRB201902598" (October/2019)}

\section{Study objective}

The main objective for this study is to improve the understanding of the college community social structure to improve the preexisting emergency communication and the overall university disaster risk management.

Section 1: Demographics

Additional

informa-

tion

Q.1 Age:

Q.2 Birth Gender

$-$

Q.3 Housing

Q.4 Marital Status

Q.5 Country of origin:

$\begin{array}{ll}\text { Male } & \text { Female } \\ \text { On-Campus } & \text { Off-Campus } \\ \text { Single } & \text { Married }\end{array}$

Q.6 How long have you lived in Florida (or any hurricane-threatened area in the U.S)?

Section 2: Hurricane general knowledge

Q.7 Do you know the difference between a hurricane-watch and a hurricane-warning? Yes No

Q.8 When does the hurricane season start and when does it end? (Answer in months) Start: End:

Q.9 What is the possibility of hurricane category 4(or 5) striking Gainesville in any -\% given year? (Make a guess if you don't know)

Q.10 Have you ever (or any person close to you) directly been impacted by any hurricane? Yes No

Q.11 Do you know the exact location of shelters on campus? $\quad$ Yes No

Section 3: Psychological impact and emergency communication and

Q.12 On scale 1 to 10 (where 1 means Not-Worried, and 10 means Extremely-

Worried) How worried were you during the last hurricane alert (Hurricane

Dorian)?

Q.13 On scale 1 to 10 (where 1 means Not-Overwhelmed, and 10 means ExtremelyOverwhelmed) How overwhelmed were you by the amount of information shared by UF about Hurricane Dorian?

Q.14 How did you receive the Dorian Hurricane Alert from UF?

\begin{tabular}{|c|c|c|c|c|c|}
\hline Email & $\begin{array}{l}\text { Text mes- } \\
\text { sage }\end{array}$ & Phone Call & $\begin{array}{c}\text { University } \\
\text { Social } \\
\text { Media }\end{array}$ & $\begin{array}{l}\text { University } \\
\text { Website }\end{array}$ & $\begin{array}{l}\text { Direct instruction from } \\
\text { university staff }\end{array}$ \\
\hline
\end{tabular}

Q.15 What is the best way that UF can contact you through for Hurricane Alert?

$\begin{array}{cccc}\text { Text mes- } & \text { Phone Call } & \text { University } & \text { University } \\ \text { sage } & \text { Social } & \text { Website } & \begin{array}{c}\text { Direct instruction from } \\ \text { university staff }\end{array} \\ & \text { Media } & & \end{array}$

Section 4: Hurricane preparedness (Select all that apply)

Q.16 On scale 1 to 10 (where 1 means Not-Ready, and 10 means fully-Ready) How ready do you believe you were if Hurricane Dorian would have reached Gainesville?

Q.17 On scale 1 to 10 (where 1 means Not-Satisfied, and 10 means Fully-Satisfied) How satisfied are you when it comes to UF hurricane alerting process? 
Section 4: Hurricane preparedness (Select all that apply)

Q.18 On scale 1 to 10 (where 1 means Extremely-Disagree, and 10 means Extremely-Agree) Do you think providing a shortened hurricane training once a year will improve your overall preparedness for hurricanes?

Q.19 Taking into consideration that a standard disaster supply kit includes a minimum of 3 days (72 h) worth of basic supplies. For the last hurricane alert (Hurricane Dorian), did you get the following items?

A. Water (minimum guidance is 1 gallon per day, per person)

$\begin{array}{lll}\text { Yes } & \text { No } & - \\ \text { Yes } & \text { No } & - \\ \text { Yes } & \text { No } & - \\ \text { Yes } & \text { No } & - \\ \text { Yes } & \text { No } & - \\ \text { Yes } & \text { No } & - \\ \text { Yes } & \text { No } & \text { Not Applicable } \\ \text { Yes } & \text { No } & - \\ \text { Yes } & \text { No } & - \\ \text { Yes } & \text { No } & - \\ \text { Yes } & \text { No } & \text { Not Applicable }\end{array}$

B. Food (types that do not require refrigeration or preparation)

C. Battery-Powered Radio (to stay up to date with weather conditions)

D. Flashlight

E. Batteries

F. First-Aid Supplies (pain relievers, Band-Aids, antibacterial ointment, etc.)

G. Special Needs Items (such as prescription medications)

H. Hygiene items - Toiletries

I. Personal Important Documents

J. Some Cash/Money

K. Pet Supplies

\section{Declarations}

Conflict of interest The auhors declare that they do not have conflict of interest.

\section{References}

Abukhalaf AHI, von Meding J (2020) Communication challenges in campus emergency planning: the case of hurricane dorian in florida. Nat Hazards 104(2):1535. https://doi.org/10.1007/s11069-020-04231-1

Abukhalaf AHI, von Meding J (2021) Psycholinguistics and emergency communication: A qualitative descriptive study. Int J Dis Risk Reduct 55:102061. https://doi.org/10.1016/j.ijdrr.2021.102061

Abukhalaf AHI, von Meding J (2021b) Emergency communications, second languages and hurricane season. Science X. Accessed 24 May 2021 from https://sciencex.com/news/2021-05-emergency-langu ages-hurricane-season.html. https://doi.org/10.13140/RG.2.2.15110.70722

Abusal D (2018) Technical project management: union of systems engineering processes with project management processes Available from Dissertations \& Theses @ University of Texas - El Paso. Accessed from https://search.proquest.com/docview/2175654268

Alachua Collector (2020, December 9) Accessed from https://www.alachuacollector.com/driver-license/\# gen_info

Alachua County (2020, December 14) Accessed from https://www.alachuacounty.us/Pages/floodzones.aspx

Athanasopoulos P (2007) Interaction between grammatical categories and cognition in bilinguals: the role of proficiency, cultural immersion, and language of instruction. Lang Cog Process 22(5):689-699. https://doi.org/10.1080/01690960601049347

Bodenreider C, Wright L, Barr O, Xu K, Wilson S (2019) Assessment of social, economic, and geographic vulnerability pre- and post-hurricane Harvey in Houston. Texas Environ Justice 12(4):182-193. https:// doi.org/10.1089/env.2019.0001

Boon HJ, Pagliano P, Brown L, Tsey K (2012) An assessment of policies guiding school emergency disaster management for students with disabilities in Australia. J Policy Prac Intell Disabil 9(1):17-26. https:// doi.org/10.1111/j.1741-1130.2012.00331.x

Chmutina K, Sadler N, von Meding J, Abukhalaf AHI (2020) Lost (and found?) in translation: key terminology in disaster studies. Disaster Prevent Manag 30(2):149-162. https://doi.org/10.1108/ DPM-07-2020-0232 
Chmutina K, Sadler N, von Meding J, Abukhalaf AHI (2021), How the english language dominates disaster research and practice, relations E-International, ISSN 2053-8626. https://doi.org/10.13140/RG.2.2. 12007.57761

Christal N, Davis MC, Weber SE, Schulenberg, \& John J. Green (2019) University students' disaster preparedness: a focus group study

Coleman CT (2008) Post-disaster effects of hurricane Katrina on significantly affected college students compared to moderately affected college students Available from ProQuest One Academic Eastern Edition. Accessed from https://search.proquest.com/docview/304466105

Esnard A, Lai B, Wyczalkowski C, Shah H (2018) School vulnerability to disaster:examination of school closure, demographic, and exposure factors in hurricane Ike's wind swath. Nat Hazards 90(2):513535. https://doi.org/10.1007/s11069-017-3057-2

Fellows RF, Liu AM (2015) Research methods for construction, 4th edn. John Wiley \& Sons, Amsterdam

Findley DA (2015) Factors influencing college student preparedness for severe weather. Available from Dissertations \& Theses @ Oklahoma State University - Stillwater. Accessed from https://search.proquest. com/docview/1853893049

Franco M, Hsiao Y, Gnilka PB, Ashby JS (2018) Acculturative stress, social support, and career outcome expectations among international students. Int J Educ Vocat Guidance 19(2):275-291. https://doi.org/ 10.1007/s10775-018-9380-7

Gómez O (2013) Lessons from international students' reaction to the 2011 great east japan earthquake: the case of the school of engineering at Tohoku University. Int J Disaster Risk Sci 4(3):137-149. https:// doi.org/10.1007/s13753-013-0015-9

Gordon R, McDermott C, Lalas TA, J (2017) Challenges associated with cross-cultural and at-risk student engagement. Information Science Reference

Gutierrez D, Hollister D, Beninati A (2005) Hurricane madness: teaching, learning and the importance of flexibility in the wake of disaster. J Coll Teach Learn (TLC) 2(2). https://doi.org/10.19030/tlc.v2i2. 1778

He X (2007) International students vulnerability to emergency events: does tenure of residence make a difference? Papers of the Applied Geography Conference. 30, 257-266

He X, Tiefenbacher J, Samson EL (2007) Hurricane evacuation behavior in domestic and international college students: the influences of environmental familiarity, expressed hurricane evacuation, and personal experience. J Emerg Manag 5(6):61-69

Jean-Pierre J (2018) The experiences of and responses to linguicism of quebec English-speaking and francoontarian postsecondary students. Can Rev Sociol 55(4):510-531. https://doi.org/10.1111/cars.12220

Kang S (2018) Research in brief. Lancet Diabetes Endocrinol 6(3):171. https://doi.org/10.1016/S2213$8587(16) 30061-4$

Lippi-Green R (2012) English with an accent: language, ideology, and discrimination in the United States (Second edn.). Routledge, Abingdon, Oxon. Retrieved from https://www.routledge.com/English-withan-Accent-Language-Ideology-and-Discrimination-in-the-United/Lippi-Green/p/book/9780415559119

Madden S (2017) The clock is ticking: temporal dynamics of campus emergency notifications. J Contingencies Crisis Manag 25(4):370-375. https://doi.org/10.1111/1468-5973.12162

Manoj BS, Baker A (2007, Mar 1,). Communication challenges in emergency response. Communications of the ACM, 50, 51-53. https://doi.org/10.1145/1226736.1226765 Accessed from http://dl.acm.org/citat ion.cfm? id $=1226765$

Martin CD, Thierry G, Kuipers J, Boutonnet B, Foucart A, Costa A (2013) Bilinguals reading in their second language do not predict upcoming words as native readers do. J Mem Lang 69(4):574-588. https:// doi.org/10.1016/j.jml.2013.08.001

Méndez M, Flores-Haro G, Zucker L (2020) The (in)visible victims of disaster: understanding the vulnerability of undocumented Latino/a and indigenous immigrants. Geoforum 116:50-62. https://doi.org/ 10.1016/j.geoforum.2020.07.007

Miller GA (1963) Language and communication. McGraw-Hill, New York

Miller GA (1967) Psychology of communication. Penguin Books, Middlesex

National Academies Press (2011) Public response to alerts and warnings on mobile devices: current knowledge and research gaps. Accessed from https://www.nap.edu/catalog/13076/public-response-to-alertsand-warningson-mobile-devices-summary

National Hurricane Center (2019) Hurricane dorian. SIRS Multimedia, Accessed from https://search.proqu est.com/docview/2305636153

O’Brien S, Federici FM (2019) Crisis translation: considering language needs in multilingual disaster settings. Disaster Prevention and Management, ahead-of-print(ahead-of-print), 129-143. https://doi.org/ 10.1108/dpm-11-2018-0373 
O'Brien S, Federici F, Cadwell P, Marlowe J, Gerber B (2018) Language translation during disaster: a comparative analysis of five national approaches. Int J Dis Risk Reduct 31:627-636. https://doi.org/10. 1016/j.ijdrr.2018.07.006

Oktari RS, Munadi K, Ridha M (2014) Effectiveness of dissemination and communication element of tsunami early warning system in aceh. Proc Econ Finance 18:136-142. https://doi.org/10.1016/S22125671(14)00923-X

Oliver R, Exell M (2020) Identity, translanguaging, linguicism and racism: the experience of Australian aboriginal people living in a remote community. Int J Bilingual Educat Bilingualism 23(7):819-832. https://doi.org/10.1080/13670050.2020.1713722

O’Neill N (2020) Gainesville's affordable housing crisis worsening amid pandemic. Accessed from https:// www.alligator.org

Page A, Chahboun S (2019) Emerging empowerment of international students: how international student literature has shifted to include the students' voices. High Educ 78(5):871-885. https://doi.org/10.1007/ s10734-019-00375-7

Patten R, Ruddell R, Thomas MO (2019) Campus emergency notification systems: lessons learned from a miscommunication. Campus Security Report 15(9):1-5. https://doi.org/10.1002/casr.30459

Prost SG, Lemieux CM, Ai AL (2016) Social work students in the aftermath of hurricanes Katrina and Rita: correlates of post-disaster substance use as a negative coping mechanism. Soc Work Educat 35(7):825-844. https://doi.org/10.1080/02615479.2016.1187720

Qin K, Li G (2020) Understanding immigrant youths' negotiation of racialized masculinities in one U.S. high school: An intersectionality lens on race, gender, and language. Sexuality Culture 24(4):10461063. https://doi.org/10.1007/s12119-020-09751-3

Reed KB, Macuare KA (2019) University of South Florida. Technol Innovat 20(3):337-342. https://doi.org/ $10.21300 / 20.1-2.2018 .337$

Regional Transit System (2020, December 15) Accessed from http://go-rts.com/about-rts/\#generalinfo

Schwalbe K (2016) Revised, an introduction to project management, fifth edition: with a brief guide to Microsoft Project Professional 2016. Schwalbe Publishing, Minneapolis

Shaw MD (2016) Organizational change as a function of disaster recovery: lessons from gulf coast institutions. Coll Stud Affairs J 34(3):62-75. https://doi.org/10.1353/csj.2016.0019

Sheldon P (2018) Emergency alert communications on college campuses: understanding students' perceptions of the severity of a crisis and their intentions to share the alert with parents and friends. West $\mathrm{J}$ Commun 82(1):100-116. https://doi.org/10.1080/10570314.2017.1308005

Sheldon P, Antony MG (2018) Sharing emergency alerts on a college campus: How gender and technology matter. South Commun J 83(3):167-178. https://doi.org/10.1080/1041794X.2018.1437467

Simms JL, Kusenbach M, Tobin GA (2013) Equally unprepared: assessing the hurricane vulnerability of undergraduate students SelectedWorks. Accessed from https://works.bepress.com/jlsimms/2

St. Cyr JF (2005) At risk: natural hazards, people's vulnerability, and disasters. J Homel Secur Emerg Manage 2(2):4. https://doi.org/10.2202/1547-7355.1131

Tang J, Feng J (2018) Residents' disaster preparedness after the meinong Taiwan earthquake: a test of protection motivation theory. Int J Environ Res Public Health 15(7):1434. https://doi.org/10.3390/ijerp h15071434

Tao G (2019) Globalization of English: Loss of minority languages and cultural destruction. International Forum of Teaching and Studies, 15(2), 36-44. Retrieved from https://search.proquest.com/docview/ 2308462599

Teo M, Goonetilleke A, Deilami K, Ahankoob A, Lawie M (2019) Engaging residents from different ethnic and language backgrounds in disaster preparedness. International Journal of Disaster Risk Reduction 39:101245. https://doi.org/10.1016/j.ijdrr.2019.101245

Thierry G (2016) Neurolinguistic relativity: how language flexes human perception and cognition. Lang Learn 66(3):690-713. https://doi.org/10.1111/lang.12186

Thorup-Binger C (2018) Vulnerability and capacities of international students in the face of disasters in Auckland, New Zealand: a qualitative descriptive study. Accessed from http://hdl.handle.net/10292/ 11803

Thorup-Binger C, Charania NA (2019) Vulnerability and capacities of international students in the face of disasters in Auckland, New Zealand: a qualitative descriptive study. Int J Dis Risk Reduct 39:101136. https://doi.org/10.1016/j.ijdrr.2019.101136

Tkachuck MA, Schulenberg SE, Lair EC (2018) Natural disaster preparedness in college students: implications for institutions of higher learning. J Am Coll Health 66(4):269-279. https://doi.org/10.1080/ 07448481.2018 .1431897

Tran LT (2020) Teaching and engaging international students: people-to-people connections and people-topeople empathy. J Int Stud 10(3):XII-XVII. https://doi.org/10.32674/jis.v10i3.2005 
Uekusa S (2009) Everyday experiences of linguicism: a sociological critique of linguistic human rights. Accessed from https://scholarworks.calstate.edu/concern/theses/gf06g327n

Uekusa S (2011) The perceived role of accent in micro-level linguicism. Accessed from https://www.resea rchgate.net/publication/255574124_The_Perceived_Role_of_Accent_in_Micro-Level_Linguicism

Uekusa S (2018) Social vulnerability, resilience and capital in disasters: Immigrants, refugees and linguistic minorities in the 2010-2011 Canterbury and Tohoku disasters. Accessed from https://researchspace. auckland.ac.nz/handle/2292/45091

Uekusa S (2019) Disaster linguicism: linguistic minorities in disasters. Lang Soc 48(3):353-375. https://doi. org/10.1017/S0047404519000150

Uekusa S (2020) The paradox of social capital: a case of immigrants, refugees and linguistic minorities in the canterbury and tohoku disasters. Int J Disaster Risk Reduct 48:101625. https://doi.org/10.1016/j. ijdrr.2020.101625

Uekusa S, Matthewman S (2017) Vulnerable and resilient? Immigrants and refugees in the 2010-2011 canterbury and tohoku disasters. Int J Disaster Risk Reduct 22:355-361. https://doi.org/10.1016/j.ijdrr. 2017.02.006

University of Florida (2020, December 20) Accessed from https://ir.aa.ufl.edu/uffacts/enrollment-1/

U.S. Social Security (2020, December 17) Accessed from https://www.ssa.gov/benefits/retirement/

Volk S, Koehler T, Pudelko M (2014) Brain drain: the cognitive neuroscience of foreign language processing in multilingual organizations. Acad Manag Proc 1:10494. https://doi.org/10.5465/AMBPP.2013. 10494abstract

Watson PG, Loffredo VJ, McKee JC (2011) When a natural disaster occurs: lessons learned in meeting students' needs. J Prof Nurs 27(6):362-369. https://doi.org/10.1016/j.profnurs.2011.09.001

Publisher's Note Springer Nature remains neutral with regard to jurisdictional claims in published maps and institutional affiliations. 